\title{
Vitamin D in schizophrenia and depression: a clinical review ${ }^{\dagger}$
}

\author{
John Lally 주 \& Fiona Gaughran
}

\begin{abstract}
John Lally, MB, MSc, MRCPsych, is a psychiatrist at St Vincent's Hospital Fairview, Dublin, Ireland, and a clinical researcher in the Department of Psychosis Studies at the Institute of Psychiatry, Psychology and Neuroscience (IoPPN), King's College London, UK, and the Royal College of Surgeons in Ireland. Fiona

Gaughran, MB, BCh, BAO, FRCPI, FRCP, FRCPsych, MD, is the lead consultant in the National Psychosis Service and director of research and development at South London and Maudsley NHS Foundation Trust. She is also a reader in psychopharmacology and physical health in the Department of Psychosis Studies at the IOPPN.

Correspondence Dr John Lally, P063, Department of Psychosis Studies, Institute of Psychiatry, Psychology and Neuroscience, King's College London, De Crespigny Park, London SE5 8AF, UK. Email: john.

lally@kcl.ac.uk
\end{abstract}

First received 11 Nov 2018

Final revision 28 Jan 2019

Accepted 4 Feb 2019

\section{Copyright and usage}

(C) The Royal College of Psychiatrists 2019

${ }^{\dagger}$ See commentary, this issue.

\section{SUMMARY}

Evidence from preclinical and clinical studies supports a role for vitamin $D$ deficiency in many mental disorders. In this review, we discuss the role of vitamin $\mathrm{D}$ in the aetiology and treatment of schizophrenia and depression and their physical health comorbidities. Although observational studies support a potential association between vitamin $D$ and schizophrenia and depression, sufficient highquality evidence from clinical trials does not yet exist to establish a place for vitamin D supplementation in optimising clinical response or promoting physical health. Completed randomised controlled trials are needed to provide insights into the efficacy and safety of vitamin $D$ in the management of mental disorders.

\section{LEARNING OBJECTIVES}

After reading this article you will be able to:

- outline the epidemiology of vitamin $D$ deficiency in schizophrenia

- describe the associations of vitamin D with schizophrenia and depression

- know how to assess, and consider treatment for, vitamin $\mathrm{D}$ deficiency.

\section{DECLARATION OF INTEREST}

F.G. has received support or honoraria for $\mathrm{CME}_{\text {, }}$ advisory work and lectures from Bristol-Myers Squibb, Janssen, Lundbeck, Otsuka, Roche and Sunovion, and has a family member with professional links to Lilly and GSK, including shares. She is in part funded by the National Institute for Health Research's (NIHR) Biomedical Research Centre at South London and Maudsley NHS Foundation Trust and King's College London and the South London Collaboration for Leadership in Applied Health Research \& Care Funding scheme, and by the Maudsley Charity. The views expressed in this article are those of the authors and not necessarily those of the NHS, the NIHR or the Department of Health and Social Care.

\section{KEYWORDS}

Psychosis; mood disorders; cholecalciferol.

Vitamin D is a secosteroid hormone, recognised as a neuroprotective factor with a role to play in brain development (Harms 2008; Eyles 2013). Vitamin
D promotes neurodevelopment and has a range of actions, such as promoting cell growth and differentiation, regulation of neurotransmission, immunomodulation, and antioxidant and anti-inflammatory effects. Vitamin D deficiency has been associated with various mental disorders, including mood disorders, psychotic disorders, autism and cognitive decline.

\section{Vitamin D physiology}

Vitamin D belongs to a group of fat-soluble vitamins. Its primary functions are to aid the intestinal absorption of calcium and phosphate, and to regulate bone mineralisation (Holick 2013). The two main forms of vitamin $\mathrm{D}$ are: vitamin $\mathrm{D}_{3}$ or cholecalciferol, which is formed in the skin after exposure to sunlight, and vitamin $\mathrm{D}_{2}$ or ergocalciferol, which is synthetically produced by UV irradiation of ergosterol, a steroid found in fungi.

Vitamin D levels are influenced by environment and lifestyle. Endogenous synthesis following cutaneous exposure to ultraviolet $\mathrm{B}$ radiation is the primary source (Fig. 1). A smaller proportion is acquired from dietary sources. It is not a widely appreciated fact, but nutritional sources of vitamin $D$ are relatively limited (Holick 2013). Recently a genome-wide association study (GWAS) meta-analysis of 31 studies with a total of 79366 individuals identified genetic variants at three loci (group component (GC), 7-dehydrocholesterol reductase (NADSYN1/ DHCR7) and 25-hydroxylase (CYP2R1)) influencing vitamin D levels (Jiang 2018). However, the findings were suggestive of a relatively small heritability rate for vitamin D levels, indicating that modifiable environmental factors are the main determinant of vitamin D levels.

Ultraviolet sunlight stimulation will depend on the season of the year, latitude and skin exposure. Vitamin D levels thus vary seasonally, with deficiency more common in winter and at higher latitudes, reflecting ambient levels of sunlight (Hypponen 2007), as well as in urban settings, owing to lifestyle choices and lower sunlight exposure (Holick 1995). People with more pigmented skin need more sunlight to produce vitamin $\mathrm{D}$, so are particularly affected by limited sun exposure; lower levels of vitamin D are consistently observed 


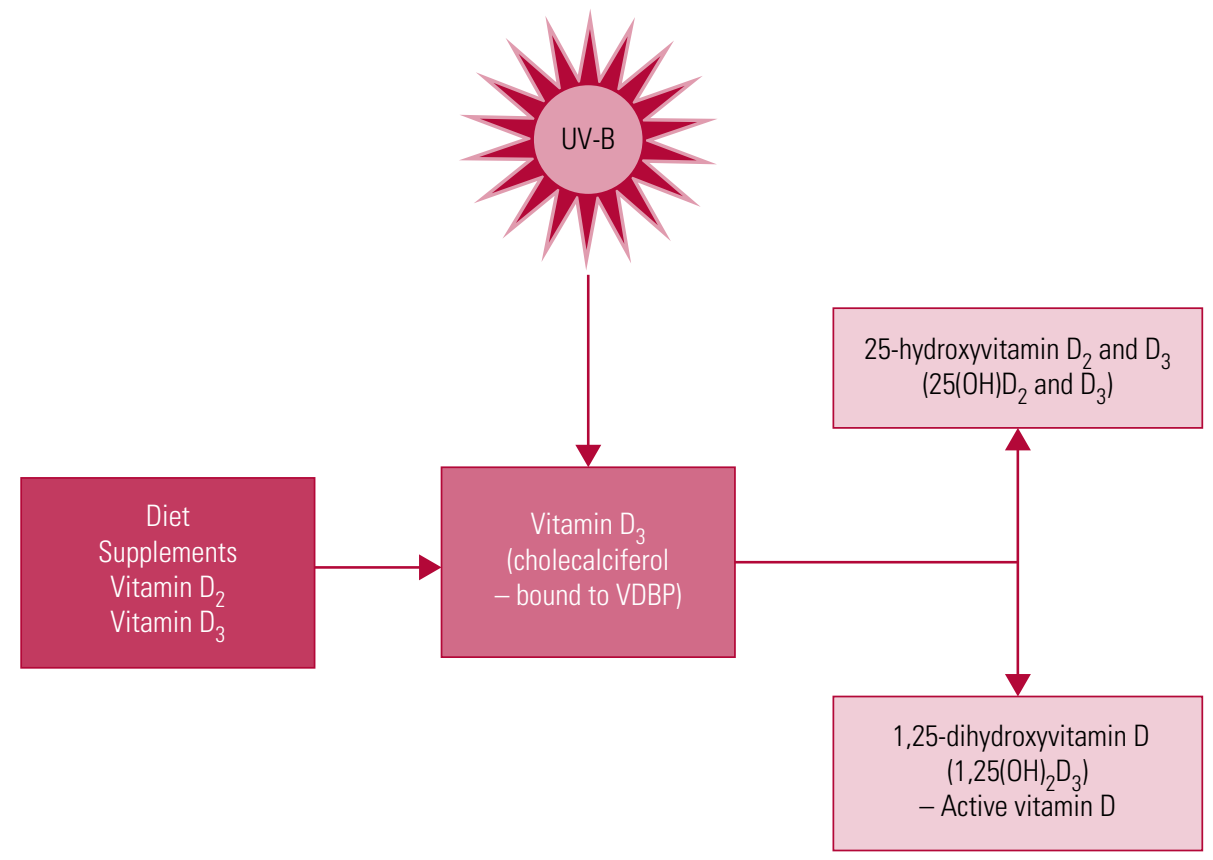

Vitamin D synthesis. UV-B, ultraviolet $B$ radiation; VDBP, vitamin D binding protein.

in Black and Asian populations (Ford 2006). Older age is associated with lower vitamin D levels, when reduced sunlight exposure and decreased ability to synthesise vitamin D cutaneously with sunlight exposure are contributing factors.

\section{Epidemiology of vitamin D deficiency}

Vitamin D deficiency is a global problem; more than a billion people worldwide are believed to have suboptimal levels (Holick 2008). A recent systematic review of 195 studies including 168000 people from 44 countries (Hilger 2014) identified that only 11\% had $25(\mathrm{OH}) \mathrm{D}$ levels $>75 \mathrm{nmol} / \mathrm{L}$, the level classed as sufficient. A summary of results is given in Table 1.

\section{Classification of vitamin D status}

Serum levels of $25(\mathrm{OH}) \mathrm{D}$, the main circulating form of vitamin $\mathrm{D}$, are usually taken as a proxy of vitamin D status (Holick 2008; Ross 2011), as it is a more stable compound than the physiologically active form $1,25(\mathrm{OH})_{2} \mathrm{D}_{3}$, with higher serum concentrations and a longer half-life (approximately 20 days compared with 7 h) (Lips 2007).

Controversy remains about what vitamin D levels are optimal (sufficient), insufficient and deficient, and we show typical thresholds in Box 1. The definitions of sufficiency as a vitamin D level $>75 \mathrm{nmol} / \mathrm{L}$ are based on observations relating to the role of $25(\mathrm{OH}) \mathrm{D}$ in calcium homeostasis and optimal calcium absorption. Parathyroid hormone levels decline with reducing concentrations of $25(\mathrm{OH}) \mathrm{D}$, although this decline plateaus and reaches a nadir at $25(\mathrm{OH}) \mathrm{D}$ concentrations of $75-100 \mathrm{nmol} / \mathrm{L}$ (equivalent to $30-40 \mathrm{ng} / \mathrm{mL}$ ) (Holick 2007). Intestinal calcium absorption is optimal at concentrations $>80 \mathrm{nmol} / \mathrm{L}$ (32 ng/mL) (Holick 2008). The definition of vitamin $\mathrm{D}$ sufficiency of $>50 \mathrm{nmol} / \mathrm{L}$ $25(\mathrm{OH}) \mathrm{D}$ is based on the observation that parathyroid hormone levels normalise with $25(\mathrm{OH}) \mathrm{D}$ concentrations of $>50 \mathrm{nmol} / \mathrm{L}$ (Ross 2011); similar levels are required to prevent osteomalacia and to ensure optimal bone function (Ebeling 2014).

The US Institute of Medicine recommends vitamin D levels $>20 \mathrm{ng} / \mathrm{mL}$ ( $>50 \mathrm{nmol} / \mathrm{L}$ ) to optimise skeletal benefits, based on trials in the general population (Ross 2011). Most recently, the Endocrine Society's clinical guidelines, based on studies of people at high risk for vitamin $\mathrm{D}$ deficiency, recommend that a $25(\mathrm{OH}) \mathrm{D}$ concentration $>30 \mathrm{ng} / \mathrm{mL}$ (>75 nmol/L) be attained to improve outcomes (Holick 2011).

\section{Vitamin D and depression}

\section{Is there a relationship?}

Research exploring the relationship between suboptimal vitamin D levels and depression risk has provided inconsistent findings. Several narrative reviews assessing the association between low vitamin D levels and depression suggest an inconclusive relationship.

A systematic review and meta-analysis of observational studies (Anglin 2013) concluded that vitamin D levels were inversely associated with the prevalence of depression. However, the observational nature of the included studies precluded drawing conclusions on a causal relationship. 
TABLE 1 Vitamin D status in populations worldwide

\begin{tabular}{|lcl|}
\hline $\begin{array}{l}\text { Serum 25(OH)D } \\
\text { concentration, } \\
\text { mean: } \mathbf{n m o l} / \mathbf{L} \text { (ng/mL) }\end{array}$ & Prevalence, \% & Classification \\
\hline$<25(<10)$ & 6.7 & Deficiency \\
$<50(<20)$ & 37 & Insufficiency \\
$>75(>30)$ & 11 & Sufficiency \\
\hline
\end{tabular}

25(OH)D, 25-hydroxyvitamin D. Source: Hilger et al (2014).

There remains a paucity of longitudinal data investigating the relationship between vitamin D and depression. The few existing studies have provided inconclusive results. A recent large-scale population-based study of 3251 adults over 55 years of age that investigated long-term associations between vitamin D serum levels and depression (Jovanova 2017) identified a cross-sectional association between low vitamin D and depression, but found no evidence for a longitudinal relationship. The cross-sectional relationship might be expected, as people who are depressed may be less able to engage in outdoor activity and may limit their sun exposure. However, if vitamin D is a risk factor for depression, then we would expect to find that vitamin $\mathrm{D}$ concentrations had a longitudinal association with depression and depressive symptoms, which was not found in that study (Jovanova 2017). This replicated previous longitudinal data which failed to identify a longitudinal association between low vitamin D and depression (Chan 2011; Toffanello 2014), although it was contradictory to findings from two other longitudinal studies (May 2010; Milaneschi 2010), which identified a relationship between suboptimal vitamin D levels and the prospective onset of depression.

BOX 1 Definitions of vitamin D status

For the ranges below, vitamin $\mathrm{D}$ status is measured in terms of $25(\mathrm{OH}) \mathrm{D}$ serum concentration.

Most common thresholds ${ }^{\mathrm{a}}$

Deficiency: $<50 \mathrm{nmol} / \mathrm{L}(20 \mathrm{ng} / \mathrm{mL})$

Insufficiency: $51-74 \mathrm{nmol} / \mathrm{L}(21-29 \mathrm{ng} / \mathrm{mL})$

Sufficiency: $>75 \mathrm{nmol} / \mathrm{L}$ ( $>30 \mathrm{ng} / \mathrm{mL}$ )

More conservative thresholds ${ }^{b}$

Deficiency: $<25 \mathrm{nmol} / \mathrm{L}$ (<10 ng/mL)

Insufficiency: $25-50 \mathrm{nmol} / \mathrm{L}(10-20 \mathrm{ng} / \mathrm{mL})$

Sufficiency: $>50 \mathrm{nmol} / \mathrm{L}$ (>20 ng/mL)

a. Holick \& Chen (2008); US Institute of Medicine: Ross et al (2011).

b. International Osteoporosis Foundation: Dawson-Hughes et al (2010).
A meta-analysis of randomised controlled trials (RCTs) of vitamin D supplementation as a treatment for depression identified six RCTs with 1203 participants $(72 \%$ females), including 71 with current depression (5 trials included participants at risk of depression and 1 trial included patients with depression). There was no significant effect of vitamin D supplementation on depression scores $(\mathrm{SMD}=$ $-0.14,95 \% \mathrm{CI}-0.41$ to $0.13, P=0.32$; OR $=0.93$, $95 \%$ CI $0.54-1.59, P=0.79$ ) (Li 2014). Both this and the above-mentioned systematic review (Anglin 2013) supported the conclusion of previous narrative reviews indicating that no clear causal relationship between suboptimal vitamin D levels and depression has been identified.

\section{Vitamin D as a therapeutic agent: augmentation trials}

In depression

Only one small randomised double-blind trial of vitamin $\mathrm{D}_{3}$ augmentation of a specific antidepressant medication in depressive disorder has taken place. Over an 8-week period there was a significant improvement in depressive symptoms in those whose fluoxetine $20 \mathrm{mg}$ daily was augmented with $1500 \mathrm{IU}$ of vitamin $\mathrm{D}_{3} \quad(n=20)$ compared with those who received fluoxetine alone $(n=20)$ (Khoraminya 2013). A controlled open label trial of antidepressant (any) augmentation with a single oral dose of $300000 \mathrm{IU}$ of vitamin $\mathrm{D}_{3} \quad(n=24)$ showed a significant improvement in depressive symptoms over a 4 -week period in comparison with use of antidepressant alone $(n=15)$ (Zanetidou 2011). Over 90\% of the included cases treated with vitamin $\mathrm{D}_{3}$ augmentation had a $25(\mathrm{OH}) \mathrm{D}$ level $<75 \mathrm{nmol} / \mathrm{L}$ (<30 ng/mL), and 80\% of the comparison group treated with antidepressants only, had a $25(\mathrm{OH}) \mathrm{D}$ level $<75 \mathrm{nmol} / \mathrm{L}$. A later RCT showed efficacy for a single dose of 300000 IU intramuscular vitamin D $(n=40)$ in improving depressive symptoms at 8 weeks following injection compared with placebo $(n=40)$, an effect not seen with the lower $150000 \mathrm{IU}$ dose $(n=40)$ (Mozaffari-Khosravi 2013).

An RCT of 78 people aged 60 and older in receipt of treatment for depression identified a non-significant change in the mean depression score between those who also received $50000 \mathrm{IU}$ of vitamin $\mathrm{D}_{3}$ weekly for 8 weeks compared with those who received a weekly placebo (although the mean vitamin D level $(22.57 \mathrm{ng} / \mathrm{mL}$ (s.d. =6.2)) in the vitamin $\mathrm{D}$ group may be considered to have been optimal) (Alavi 2018). An earlier double-blind RCT of $50000 \mathrm{IU}$ vitamin D weekly compared with placebo found a non-significant decrease in depressive symptoms over an 8-week period 
(Sepehrmanesh 2016). A double-blind RCT of dialysis patients with depression did not identify a significant reduction in depressive symptoms following treatment with 50000 IU vitamin D weekly for 52 weeks ( $n=362$ ) (Wang 2016).

\section{In bipolar depression}

There has been a single RCT of vitamin $\mathrm{D}_{3}$ augmentation in bipolar depression, with no significant difference in depression symptom scores between those treated with $5000 \mathrm{IU}$ of vitamin $\mathrm{D}_{3}$ daily $(n=16)$ and placebo $(n=17)$ after 12 weeks (Marsh 2017). This was despite a significantly higher mean increase in vitamin $\mathrm{D}$ levels in the augmentation group $(9.9 \mathrm{ng} / \mathrm{mL}$ (s.d. = 8.2)) compared with the placebo group $(1.3 \mathrm{ng} / \mathrm{mL}$ (s.d. $=4.3))$.

\section{Summary}

The RCTs to date in mood disorders have been limited by small sample sizes and heterogeneity of study populations and vitamin $\mathrm{D}$ dosing techniques. These trials have produced inconsistent findings, which provide at best a mild signal for a beneficial effect of vitamin D on mood, but which is far from conclusive.

\section{Vitamin D as a preventive agent}

\section{Effect of supplementation on depression symptom scores and mental health}

In addition to trials of vitamin $\mathrm{D}$ as a therapeutic agent in depression, RCTs have investigated vitamin $\mathrm{D}$ as a preventive agent. A few RCTs have investigated vitamin D supplementation in improving depressive symptoms or depression scale scores, and those that have done so reported inconsistent findings: some showed a positive effect (Jorde 2008; Khoraminya 2013), whereas others found no significant association (Vieth 2004; Kjærgaard 2012; Yalamanchili 2012). There was no association with improved depression and anxiety symptom scores in a cohort of young healthy adults supplemented with $5000 \mathrm{IU}$ of vitamin $\mathrm{D}_{3}$ for 6 weeks compared with placebo (Dean 2011), although there was a low prevalence of vitamin D deficiency in the test population. A randomised trial of vitamin $\mathrm{D}_{3}$ supplementation with $800 \mathrm{IU} /$ day in women aged 70 or over did not identify any significant improvement in mental health outcomes with supplementation, although the study was limited by a low level of depression in the study sample and the moderately low dose of vitamin $\mathrm{D}_{3}$ (Dumville 2006). A randomised trial investigating the effect of low-dose (600 IU daily) and high-dose (4000 IU daily) vitamin $\mathrm{D}_{3}$ (total $n=82$ ) found significant improvements in well-being for those receiving the high-dose therapy at 6-month followup (Vieth 2004). Other randomised trials have found benefits with vitamin $\mathrm{D}$ supplementation in seasonal affective disorder $(n=8$ treated with $100000 \mathrm{IU}$ of vitamin $\mathrm{D}$ and $n=7$ treated with phototherapy) (Gloth 1999) and in improving depressive symptom scores in overweight or obese (body mass index BMI $>28 \mathrm{~kg} / \mathrm{m}^{2}$ ) general hospital out-patients given $20000 \mathrm{IU}$ of vitamin $\mathrm{D}_{3}$ twice weekly compared with placebo (the participants were not vitamin D deficient nor were they clinically depressed) (Jorde 2008).

As noted, these studies have not always focused on patients with clinical depression or vitamin D deficiency. Rather, most have involved vitamin $\mathrm{D}_{3}$ supplementation in general population samples, thus limiting interpretation of their findings and contributing to inconclusiveness of findings. These studies are further limited by being underpowered, with small sample sizes and heterogeneous study populations.

\section{Vitamin D and psychotic disorders}

Vitamin D insufficiency is highly prevalent in people with schizophrenia and other psychotic disorders (Suetani 2017). In a cross-sectional study of 324 community-based people with established psychosis, $86 \%$ had suboptimal vitamin D levels $(<20 \mathrm{ng} / \mathrm{mL})$. In a systematic review (Adamson 2017), 63\% met criteria for vitamin $\mathrm{D}$ deficiency (with the threshold level to define deficiency ranging from 10 to $40 \mathrm{ng} / \mathrm{mL}$ ).

We found that vitamin D levels were lower on presentation with a first episode of psychosis than in matched healthy controls (total $n=138$ ) (Crews $2013)$ and that $80 \%(n=134)$ of individuals with a first episode had suboptimal vitamin D levels at time of first contact with services (Lally 2018). Lifestyle and physical health factors associated with an increased risk of vitamin D insufficiency or deficiency, such as smoking, increased BMI, social withdrawal and inactivity resulting in decreased sunlight exposure, are all more common in people with psychotic disorders.

Epidemiological studies have indicated that those born in late winter/early spring (Davies 2003), at higher latitudes (Saha 2006) and in urban settings have an increased risk of schizophrenia, leading to suggestions that this risk may be mediated by vitamin D deficiency. This association is further suggested by studies in Black African and Black Caribbean migrant populations, among whom vitamin D levels tend to be low. Black African and Black Caribbean migrant populations have increased rates of psychosis. Cross-sectional data in first-episode psychosis (FEP) and established 
psychosis have identified lower mean vitamin D levels in patients of Black African or Caribbean ethnicity compared with White patients (Lally 2016, 2018), although whether this might differentially affect clinical symptoms or symptomatic response to treatment has not been investigated. Prenatal vitamin $\mathrm{D}$ deficiency has been hypothesised to adversely affect fetal neural development, thus increasing the risk of schizophrenia (McGrath 1999). This possibility is supported by a Danish longitudinal case-control study which showed that vitamin D status in neonates was associated with the risk of schizophrenia (McGrath 2010) and by a birth cohort study demonstrating an increased risk of schizophrenia in Finnish males not given vitamin D supplements during the first year of life (McGrath 2004).

\section{Vitamin $D_{3}$ augmentation in schizophrenia}

The only randomised trial to date investigating vitamin $\mathrm{D}_{3}$ augmentation in schizophrenia was conducted in a population of individuals receiving clozapine for treatment-resistant schizophrenia (all with baseline vitamin $\mathrm{D}$ levels $<30 \mathrm{ng} / \mathrm{mL}$ ). At 8 weeks, there was no significant difference in psychotic symptoms between those receiving $14000 \mathrm{IU}$ per week of vitamin $\mathrm{D}_{3}(n=24)$ compared with placebo $(n=23)$, although a trend towards improved cognitive performance relating to attention and recall was detected (Krivoy 2017).

\section{Vitamin $D$ and clinical symptoms in FEP}

A major limitation of work so far in FEP is the crosssectional design of most studies, limiting any inference of a causal relationship between vitamin D and clinical status: it may as easily be that the relationship identified between symptoms and low vitamin $\mathrm{D}$, be it in acute psychotic episodes (Yuksel 2014) or in FEP (Graham 2015), may be the result, rather than a cause, of psychosis.

As mentioned above, we recently investigated the longitudinal relationship between vitamin D levels at time of first contact with services in FEP and clinical symptoms at 12 months, identifying a significant association between higher vitamin D levels at first contact for psychosis and lower negative symptoms and total psychotic symptoms at 12-month follow-up (Lally 2018). This is the first longitudinal assessment of vitamin $\mathrm{D}$ levels and associations with psychotic symptoms.

Vitamin D is considered to be neuroprotective and is postulated to have brain antioxidant properties, reducing oxidative stress (Wrzosek 2013; Nerhus 2016; Mitra 2017) by decreasing the production of the oxidant nitric oxide (Garcion 2002) and increasing the production of antioxidants such as glutathione (Garcion 1996; Wrzosek 2013). Previous studies have hypothesised that unmitigated oxidative stress can contribute to the development of negative symptoms of schizophrenia through a dysregulation of glutamate-gamma-aminobutyric acid excitatory/inhibitory responses (Sullivan 2012; Albayrak 2013), while higher glutamate levels in the anterior cingulate cortex have been associated with increased negative symptoms in first-episode schizophrenia (Egerton 2012). Vitamin D's antiinflammatory properties are supported by the finding that vitamin D supplementation can reduce levels of C-reactive protein (CRP), a marker of inflammation (Chen 2014). This is mirrored in established psychosis, in which an inverse relationship between vitamin D and CRP levels has been identified (Lally 2016).

\section{Vitamin D and physical health in psychotic disorders}

Vitamin D and cardiometabolic risk

Higher vitamin D levels have been associated with improved longer-term clinical outcomes in medical conditions, with observational studies showing inverse associations between circulating 25-hydroxyvitamin D and risks of death due to cardiovascular disease and cancer (Chowdhury 2014). However, there is as yet no consistent evidence for routine supplementation.

To date, epidemiological evidence concerning the association between vitamin D and cardiometabolic risk factors in community-dwelling individuals with established psychotic illnesses is limited. For the first time in a population with established psychosis, we identified that those with the highest levels of vitamin D have a lower prevalence of metabolic syndrome (20.5\%) compared with those in the lowest $(39.1 \%)$, second $(48.3 \%)$ and third quartile (43.1\%) of vitamin D levels (all $P<0.01$ ) (Lally 2016). This was the first large-scale study to have identified an association between decreased $25(\mathrm{OH}) \mathrm{D}$ levels and cardiovascular risk factors in psychotic illnesses. Of interest, we identified associations between hypertension and low 25(OH)D levels, which may be a causally related finding. This is suggested by findings in the general population, where low 25(OH)D levels are associated with a higher risk of incident cardiovascular disease and specifically hypertension (Wang 2008). The strongest correlations with low $25(\mathrm{OH}) \mathrm{D}$ levels were with factors related to high body fat (Lally 2016), which is supported by findings that those with increased adipose tissue stores (vitamin $\mathrm{D}$, being fat soluble, is stored in adipose tissue) due to obesity have lower circulating levels of vitamin D because of this increased storage capacity (Wortsman 2000). 


\section{Vitamin D and bone mineral density}

Osteoporosis is 2.5 times more common in schizophrenia than in controls, with $52 \%$ having low bone mass (Stubbs 2014) and significantly reduced bone mineral density (BMD) at the lumbar spine (Gomez 2016).

Only three studies to date have assessed associations between vitamin $\mathrm{D}$ and $\mathrm{BMD}$ in schizophrenia (Bergemann 2008; Hallahan 2008; Rey-Sanchez 2009). In a cross-sectional study (Hallahan 2008), 15 individuals with chronic schizophrenia, living in a long-stay residential unit, had BMD measures recorded by dual-energy X-ray absorption (DEXA) scan. There were no significant correlations between vitamin $\mathrm{D}$ levels (mean $23.8 \mathrm{nmol} / \mathrm{L}$ $($ s.d. = 8.9)) and BMD. A case-control study (ReySanchez 2009) measured BMD using quantitative ultrasound (QUS) in 73 people with schizophrenia (48 males), who were all being treated with antipsychotics. There was no significant correlation between 25(OH)D levels (females: mean $20.4 \mathrm{ng} / \mathrm{mL}$ (s.d.=26.1) (equivalent to $51.0 \mathrm{nmol} / \mathrm{L})$; males: mean $15.1 \mathrm{ng} / \mathrm{mL}$ (s.d. = 12.0) (equivalent to $37.8 \mathrm{nmol} / \mathrm{L})$ ) and phalangeal $\mathrm{BMD}$ values. However, a significant negative correlation between the parathyroid hormone and lower bone mass was identified in males and females $(r=0.347, P<0.05)$. In another case-control study (Bergemann 2008), 72 premenopausal women with schizophrenia (mean age 33.8 years (s.d. $=6.5$ ), range 20.5-45.3 years) were compared with 71 age- and sex-matched healthy controls. Those with schizophrenia had no significant difference in BMD ( $T$-score) compared with the controls. Those with schizophrenia had a significantly reduced mean $25(\mathrm{OH}) \mathrm{D}$ concentration of $16.3 \mathrm{ng} / \mathrm{mL}$ (s.d. = 7.9) compared with the controls (24.6 ng/mL (s.d. = 11.5); $P<0.001$ ), although no significant correlation between serum 25(OH)D levels and BMD were reported in the schizophrenia group.

If an individual with schizophrenia has a history of fragility fractures, or evidence of reduced BMD or osteoporosis, then supplementary calcium and vitamin $\mathrm{D}$ should be prescribed as in the general population (Aspray 2014), along with any direct treatments for osteoporosis where indicated.

\section{Managing vitamin D deficiency in psychosis and depression: do we know when to screen and treat?}

As already noted, definitions of vitamin D deficiency vary. In the UK, the National Osteoporosis Society (now the Royal Osteoporosis Society) set the following serum $25(\mathrm{OH}) \mathrm{D}$ thresholds: ' $<30 \mathrm{nmol} / \mathrm{L}$ (12 ng/mL) is deficient; $30-50 \mathrm{nmol} / \mathrm{L}(12-20 \mathrm{ng} / \mathrm{mL})$ may be inadequate in some people; $>50 \mathrm{nmol} / \mathrm{L}$ $(>20 \mathrm{ng} / \mathrm{mL})$ is sufficient for almost the whole population' (Aspray 2014). Public Health England recommends that all adults consider taking vitamin D supplements (400 IU/day) in the autumn and winter months, with year-round supplementation advised for those with darker skin pigmentation (Scientific Advisory Committee on Nutrition 2016). What does this mean for the clinical care of people with schizophrenia and depression? Should we test all patients for vitamin D deficiency? How should we interpret test results and what treatment might be considered? The answer is that we do not yet know whether and how to adapt the general population advice for use in people with psychosis and depression.

It is more likely than not that a person with established psychosis will have suboptimal vitamin D levels (Lally 2016), and a pragmatic approach is reasonable when considering vitamin $\mathrm{D}$ testing: as in high-risk general population groups, a presumptive diagnosis of insufficiency could be made, based on risk factors, without the need for (expensive) testing of vitamin D levels unless the individual is symptomatic (Aspray 2014).

It is perhaps most appropriate to measure vitamin D levels in summer or autumn, when a secular trend towards more optimal levels will be seen. It is reasonable to consider people with schizophrenia as a highrisk group for suboptimal vitamin D levels. The National Osteoporosis Society recommends that such patients, as a minimum, should be treated with lifestyle advice and over-the-counter vitamin D supplements at a dose of $400 \mathrm{IU} /$ day (Aspray 2014).

In schizophrenia and depression, if the vitamin D level is measured and is $<30 \mathrm{nmol} / \mathrm{L}(<12 \mathrm{ng} / \mathrm{mL})$, then correction should be considered, with a loading dose of $40000 \mathrm{IU}$ of colecalciferol given orally weekly for 7 weeks and vitamin D level rechecked at 12 weeks to allow the level to plateau. If the level is now sufficient (i.e. $>50 \mathrm{nmol} / \mathrm{L}(>20 \mathrm{ng} / \mathrm{mL})$, then a maintenance dose of oral colecalciferol 800-2000 IU/day should be initiated, alongside dietary advice and engagement in outdoor activity. A similar maintenance regimen is advised for people with vitamin D insufficiency $(30-50 \mathrm{nmol} / \mathrm{L}$ (12-20 ng/mL)) (Aspray 2014).

Lifestyle advice should be offered to all patients, and education that the best source of vitamin D is sensible levels of sunlight exposure. Spending 10-15 min in sunlight on most days of a week, with face and arms exposed, will suffice to ensure adequate vitamin D levels (Nowson 2012).

\section{Discussion}

Vitamin D deficiency is associated with psychotic disorders, and with depression, as well as with 
MCO answers

$1 \mathrm{~d} \quad 2$ e 3 b 4 c 5 c many other chronic physical conditions. The question remains whether vitamin $\mathrm{D}$ is a causal factor or a consequence of these illnesses. Over $90 \%$ of people with established psychosis have suboptimal vitamin D levels, but depression rates in psychotic disorders are not that high, nor are persisting psychotic symptoms universally prevalent (Lally 2017). The observed associations could be due to reverse causation, the illness affecting the vitamin D levels, although our recent prospective study, while requiring replication, opens the possibility of a direct effect of vitamin D levels on outcomes in early psychosis (Lally 2018).

The evidence that vitamin D deficiency in early life may be a risk factor for later psychosis is somewhat stronger (Eyles 2018). It may be the case that vitamin $\mathrm{D}$ at suboptimal levels is no longer neuroprotective, perhaps owing to the loss of its antioxidant or anti-inflammatory effects, leaving the person more vulnerable to emerging illnesses such as psychosis or depression.

In terms of supplementation, randomised trials fail to indicate symptom improvements with vitamin D augmentation in schizophrenia and depression. Nevertheless, vitamin D testing and supplementation has crept into routine medical practice, with the assumption that optimisation of vitamin D levels will have longer-term benefits for physical health. However, evidence for this is lacking, even in the general population (Manson 2019).

\section{Conclusions}

Vitamin D deficiency has been associated with poorer mental health, depression and psychotic disorders, as well as with chronic physical conditions. However, the evidence base establishing vitamin D as a potential cause rather than consequence of depression is lacking, although there is some evidence that developmental vitamin $\mathrm{D}$ deficiency may be pertinent to psychosis risk.

Well-designed clinical trials are needed to further study the relationship between repletion of vitamin D stores and clinical outcomes in patients with depression and schizophrenia before routine testing and supplementation can be recommended. In the meantime, the guidelines for the general population should be followed, bearing in mind that the risks of vitamin D deficiency in those with psychosis and depression are higher than in the general population.

\section{References}

Adamson J, Lally J, Gaughran F, et al (2017) Correlates of vitamin D in psychotic disorders: a comprehensive systematic review. Psychiatry Research, 249: 78-85

Alavi NM, Khademalhoseini S, Vakili Z, et al (2018) Effect of vitamin D supplementation on depression in elderly patients: a randomized clinical trial. Clinical Nutrition, Sep 19: doi 10.1016/j.clnu.2018.09.011 [Epub ahead of print].

Albayrak Y, Ünsal C, Beyazyüz M, et al (2013) Reduced total antioxidant level and increased oxidative stress in patients with deficit schizophrenia: a preliminary study. Progress in Neuro-Psychopharmacology \& Biological Psychiatry, 45: 144-9.

Anglin RE, Samaan Z, Walter SD, et al (2013) Vitamin D deficiency and depression in adults: systematic review and meta-analysis. British Journal of Psychiatry, 202: 100-7.

Aspray TJ, Bowring C, Fraser W, et al (2014) National Osteoporosis Society vitamin D guideline summary. Age and Ageing, 43: 592-5.

Bergemann N, Parzer P, Mundt C, et al (2008) High bone turnover but normal bone mineral density in women suffering from schizophrenia. Psychological Medicine, 38: 1195-201.

Chan R, Chan D, Woo J, et al (2011) Association between serum 25-hydroxyvitamin $\mathrm{D}$ and psychological health in older Chinese men in a cohort study. Journal of Affective Disorders, 130: 251-9.

Chen N, Wan Z, Han SF, et al (2014) Effect of vitamin D supplementation on the level of circulating high-sensitivity C-reactive protein: a meta-analysis of randomized controlled trials. Nutrients, 6: 2206-16.

Chowdhury R, Kunutsor S, Vitezova A, et al (2014) Vitamin D and risk of cause specific death: systematic review and meta-analysis of observational cohort and randomised intervention studies. BMJ, 348: g1903.

Crews M, Lally J, Gardner-Sood P, et al (2013) Vitamin D deficiency in first episode psychosis: a case-control study. Schizophrenia Research, 150: 533-7.

Davies G, Welham J, Chant D, et al (2003) A systematic review and metaanalysis of Northern Hemisphere season of birth studies in schizophrenia. Schizophrenia Bulletin, 29: 587-93.

Dawson-Hughes B, Mithal A, Bonjour J-P, et al (2010) IOF position statement: vitamin $\mathrm{D}$ recommendations for older adults. Osteoporosis International, 21: 1151-4.

Dean AJ, Bellgrove MA, Hall T, et al (2011) Effects of vitamin D supplementation on cognitive and emotional functioning in young adults - a randomised controlled trial. PLoS One, 6: e25966.

Dumville JC, Miles JN, Porthouse J, et al (2006) Can vitamin D supplementation prevent winter-time blues? A randomised trial among older women. Journal of Nutrition, Health and Aging, 10: 151-3.

Ebeling PR (2014) Vitamin D and bone health: epidemiologic studies. BoneKEy Reports, 3: 511

Egerton A, Brugger S, Raffin M, et al (2012) Anterior cingulate glutamate levels related to clinical status following treatment in first-episode schizophrenia. Neuropsychopharmacology, 37: 2515-21.

Eyles DW, Burne TH, McGrath JJ (2013) Vitamin D, effects on brain development, adult brain function and the links between low levels of vitamin $D$ and neuropsychiatric disease. Frontiers in Neuroendocrinology, 34: 47-64.

Eyles DW, Trzaskowski M, Vinkhuyzen AAE, et al (2018) The association between neonatal vitamin D status and risk of schizophrenia. Scientific Reports, 8: 17692.

Ford L, Graham V, Wall A, et al (2006) Vitamin D concentrations in an UK inner-city multicultural outpatient population. Annals of Clinical Biochemistry, 43: 468-73.

Garcion E, Thanh XD, Bled F, et al (1996) 1,25-Dihydroxyvitamin D3 regulates gamma 1 transpeptidase activity in rat brain. Neuroscience Letters, 216: 183-6.

Garcion E, Wion-Barbot N, Montero-Menei CN, et al (2002) New clues about vitamin D functions in the nervous system. Trends in Endocrinology and Metabolism, 13: 100-5.

Gloth FM III, Alam W, Hollis B (1999) Vitamin D vs broad spectrum phototherapy in the treatment of seasonal affective disorder. Journal of Nutrition, Health and Aging, 3: 5-7.

Gomez L, Stubbs B, Shirazi A, et al (2016) Lower bone mineral density at the hip and lumbar spine in people with psychosis versus controls: a comprehensive review and skeletal site-specific meta-analysis. Current Osteoporosis Reports, 14: 249-59. 
Graham KA, Keefe RS, Lieberman JA, et al (2015) Relationship of low vitamin D status with positive, negative and cognitive symptom domains in people with first-episode schizophrenia. Early Intervention in Psychiatry, 9: $397-405$.

Hallahan B, Lyons D, Doyle P (2008) Bone mineral density and general health of long-term residential psychiatric inpatients. Irish Journal of Psychological Medicine, 25: 95-9.

Harms LR, Eyles DW, McGrath JJ, et al (2008) Developmental vitamin D deficiency alters adult behaviour in 129/SvJ and C57BL/6J mice. Behavioural Brain Research, 187: 343-50.

Hilger J, Friedel A, Herr R, et al (2014) A systematic review of vitamin D status in populations worldwide. British Journal of Nutrition, 111: 23-45.

Holick MF (1995) Environmental factors that influence the cutaneous production of vitamin D. American Journal of Clinical Nutrition, 61: 638S-45S.

Holick MF, Chen TC, Lu Z, et al (2007) Vitamin D and skin physiology: a D-lightful story. Journal of Bone and Mineral Research, 22(suppl 2): V28-33.

Holick M, Chen T (2008) Vitamin D deficiency: a worldwide problem with health consequences. American Journal of Clinical Nutrition, 87: 1080S-6S.

Holick MF, Binkley NC, Bischoff-Ferrari HA, et al (2011) Evaluation, treatment, and prevention of vitamin D deficiency: an Endocrine Society clinical practice guideline. Journal of Clinical Endocrinology and Metabolism, 96: 1911-30.

Holick MF (2013) Vitamin D: physiology, dietary sources, and requirements. In Encyclopedia of Human Nutrition (3rd edn) (eds B Caballero, L Allen, A Prentice): 323-32. Academic Press

Hypponen E, Power C (2007) Hypovitaminosis D in British adults at age 45 y: nationwide cohort study of dietary and lifestyle predictors. American Journal of Clinical Nutrition, 85: 860-8.

Jiang X, O'Reilly PF, Aschard H, et al (2018) Genome-wide association study in 79,366 European-ancestry individuals informs the genetic architecture of 25-hydroxyvitamin D levels. Nature Communications, 9: 260.

Jorde R, Sneve M, Figenschau Y, et al (2008) Effects of vitamin D supplementation on symptoms of depression in overweight and obese subjects: randomized double blind trial. Journal of Internal Medicine, 264: 599-609.

Jovanova O, Aarts N, Noordam R, et al (2017) Vitamin D serum levels are cross-sectionally but not prospectively associated with late-life depression. Acta Psychiatrica Scandinavica, 135: 185-94.

Khoraminya N, Tehrani-Doost M, Jazayeri S, et al (2013) Therapeutic effects of vitamin $D$ as adjunctive therapy to fluoxetine in patients with major depressive disorder. Australian and New Zealand Journal of Psychiatry, 47: 271-5

Kjærgaard M, Waterloo K, Wang CE, et al (2012) Effect of vitamin D supplement on depression scores in people with low levels of serum 25hydroxyvitamin D: nested case-control study and randomised clinical trial. British Journal of Psychiatry, 201: 360-8.

Krivoy A, Onn R, Vilner Y, et al (2017) Vitamin D supplementation in chronic schizophrenia patients treated with clozapine: a randomized, double-blind, placebo-controlled clinical trial. EBioMedicine, 26: 138-45.

Lally J, Gardner-Sood P, Firdosi M, et al (2016) Clinical correlates of vitamin D deficiency in established psychosis. BMC Psychiatry, 16: 1-9.

Lally J, Ajnakina O, Stubbs B, et al (2017) Remission and recovery from first-episode psychosis in adults: systematic review and meta-analysis of long-term outcome studies. British Journal of Psychiatry, 211: 350-8.

Lally J, Ajnakina O, Singh N, et al (2018) Vitamin D and clinical symptoms in First Episode Psychosis (FEP): a prospective cohort study. Schizophrenia Research, Aug 25: doi 10.1016/j.schres.2018.08.011 [Epub ahead of print].

Li G, Mbuagbaw L, Samaan Z, et al (2014) Efficacy of vitamin D supplementation in depression in adults: a systematic review. Journal of Clinical Endocrinology and Metabolism, 99: 757-67.

Lips $\mathrm{P}$ (2007) Relative value of 25(OH)D and 1,25(OH)2D measurements. Journal of Bone and Mineral Research, 22: 1668-71.

Manson JE, Cook NR, Lee IM, et al (2019) Vitamin D supplements and prevention of cancer and cardiovascular disease. New England Journal of Medicine, 380: 33-44.
Marsh WK, Penny JL, Rothschild AJ (2017) Vitamin D supplementation in bipolar depression: a double blind placebo controlled trial. Journal of Psychiatric Research, 95: 48-53.

May HT, Bair TL, Lappe DL, et al (2010) Association of vitamin D levels with incident depression among a general cardiovascular population. American Heart Journal, 159: 1037-43.

McGrath J (1999) Hypothesis: is low prenatal vitamin D a risk-modifying factor for schizophrenia? Schizophrenia Research, 40: 173-7.

McGrath J, Saari K, Hakko H, et al (2004) Vitamin D supplementation during the first year of life and risk of schizophrenia: a Finnish birth cohort study. Schizophrenia Research, 67: 237-45.

McGrath JJ, Eyles DW, Pedersen CB, et al (2010) Neonatal vitamin D status and risk of schizophrenia: a population-based case-control study. Archives of General Psychiatry, 67: 889-94.

Milaneschi Y, Shardell M, Corsi AM, et al (2010) Serum 25-hydroxyvitamin $D$ and depressive symptoms in older women and men. Journal of Clinical Endocrinology and Metabolism, 95: 3225-33.

Mitra S, Natarajan R, Ziedonis D, et al (2017) Antioxidant and anti-inflammatory nutrient status, supplementation, and mechanisms in patients with schizophrenia. Progress in Neuro-Psychopharmacology \& Biological Psychiatry, 78: 1-11.

Mozaffari-Khosravi H, Nabizade L, Yassini-Ardakani SM, et al (2013) The effect of 2 different single injections of high dose of vitamin $D$ on improving the depression in depressed patients with vitamin $D$ deficiency: a randomized clinical trial. Journal of Clinical Psychopharmacology, 33: 378-85.

Nerhus M, Berg A0, Kvitland LR, et al (2016) Low vitamin D is associated with negative and depressive symptoms in psychotic disorders. Schizophrenia Research, 178: 44-9.

Nowson CA, McGrath JJ, Ebeling PR, et al (2012) Vitamin D and health in adults in Australia and New Zealand: a position statement. Medical Journal of Australia, 196: 686-7.

Rey-Sanchez P, Lavado-Garcia JM, Canal-Macias ML, et al (2009) Ultrasound bone mass in schizophrenic patients on antipsychotic therapy. Human Psychopharmacology, 24: 49-54.

Ross AC, Manson JE, Abrams SA, et al (2011) The 2011 report on dietary reference intakes for calcium and vitamin $D$ from the Institute of Medicine: what clinicians need to know. Journal of Clinical Endocrinology and Metabolism, 96: 53-8.

Saha S, Chant DC, Welham JL, et al (2006) The incidence and prevalence of schizophrenia varies with latitude. Acta Psychiatrica Scandinavica, 114: $36-9$

Scientific Advisory Committee on Nutrition. Vitamin D and Health. SACN 2016 (https://www.gov.uk/government/publications/sacn-vitamin-d-andhealth-report).

Sepehrmanesh Z, Kolahdooz F, Abedi F, et al (2016) Vitamin D supplementation affects the Beck Depression Inventory, insulin resistance, and biomarkers of oxidative stress in patients with major depressive disorder: a randomized, controlled clinical trial. Journal of Nutrition, 146: 243-8.

Stubbs B, de Hert M, Sepehry AA, et al (2014) A meta-analysis of prevalence estimates and moderators of low bone mass in people with schizophrenia. Acta Psychiatrica Scandinavica, 130: 470-86.

Suetani S, Saha S, Eyles DW, et al (2017) Prevalence and correlates of suboptimal vitamin D status in people living with psychotic disorders: data from the Australian Survey of High Impact Psychosis. Australian and New Zealand Journal of Psychiatry, 9: 921-9.

Sullivan EM, O'Donnell P (2012) Inhibitory interneurons, oxidative stress, and schizophrenia. Schizophrenia Bulletin, 38: 373-6.

Toffanello ED, Sergi G, Veronese N, et al (2014) Serum 25-hydroxyvitamin $\mathrm{d}$ and the onset of late-life depressive mood in older men and women: the Pro.V.A. study. Journals of Gerontology. Series A, 69: 1554-61.

Vieth R, Kimball S, Hu A, et al (2004) Randomized comparison of the effects of the vitamin D3 adequate intake versus $100 \mathrm{mcg}$ (4000 IU) per day on biochemical responses and the wellbeing of patients. Nutrition Journal, 3: 8 .

Wang TJ, Pencina MJ, Booth SL, et al (2008) Vitamin D deficiency and risk of cardiovascular disease. Circulation, 117: 503-11. 
Wang Y, Liu Y, Lian Y, et al (2016) Efficacy of high-dose supplementation with oral vitamin D3 on depressive symptoms in dialysis patients with vitamin D3 insufficiency: a prospective, randomized, double-blind study. Journal of Clinical Psychopharmacology, 36: 229-35.

Wortsman J, Matsuoka LY, Chen TC, et al (2000) Decreased bioavailability of vitamin D in obesity. American Journal of Clinical Nutrition, 72: 690-3.

Wrzosek M, Łukaszkiewicz J, Wrzosek M, et al (2013) Vitamin D and the central nervous system. Pharmacological Reports, 65: 271-8.

Yalamanchili V, Gallagher JC (2012) Treatment with hormone therapy and calcitriol did not affect depression in older postmenopausal women: no interaction with estrogen and vitamin $\mathrm{D}$ receptor genotype polymorphisms. Menopause, 19: 697-703.

Yuksel RN, Altunsoy N, Tikir B, et al (2014) Correlation between total vitamin D levels and psychotic psychopathology in patients with schizophrenia: therapeutic implications for add-on vitamin D augmentation. Therapeutic Advances in Psychopharmacology, 4: $268-75$.

Zanetidou S, Belvederi Murri M, Buffa A, et al (2011) Vitamin D supplements in geriatric major depression. International Journal of Geriatric Psychiatry, 26: 1209-10.

\section{MCOs}

Select the single best option for each question stem

1 Evidence to suggest that vitamin D may be an aetiological factor in schizophrenia include all of the following except:

a increased incidence of schizophrenia at higher latitudes

b increased prevalence of schizophrenia in people of African ethnicity

c raised incidence of schizophrenia in urban settings

$\mathrm{d}$ association between lower dairy intake and schizophrenia

e increased incidence in those born during the winter.

2 As regards vitamin $D$ augmentation in depression:

a vitamin $D$ augmentation should be given to all people with depression
4 The physiologically active form of vitamin D is:

a cholecalciferol

b $25(\mathrm{OH})_{2} \mathrm{D}_{3}$

c $1,25(\mathrm{OH})_{2} \mathrm{D}_{3}$

d $25(\mathrm{OH})_{3} \mathrm{D}_{3}$

e vitamin $\mathrm{D}_{2}$. those who are housebound

e augmentation trials may be best focused on depressed patients with vitamin $\mathrm{D}$ deficiency.

3 As regards vitamin $D$ deficiency in schizophrenia:

5 Vitamin $D$ deficiency is defined by levels:

a $<50 \mathrm{nmol} / \mathrm{L}$

b $<100 \mathrm{nmol} / \mathrm{L}$

c $<25 \mathrm{nmol} / \mathrm{L}$

a low milk intake is a common cause of vitamin D $\quad d<75 \mathrm{nmol} / \mathrm{L}$ deficiency schizophrenia

b most vitamin $D$ does not come from food so dietary intake is not an important factor

c it explains why people living in rural areas have higher risk of schizophrenia

d it explains why schizophrenia is only found in people living at high latitudes

e it explains why those born in summer months have higher risk of schizophrenia. 